\title{
In Vitro Studies on the Relative Sensitivity to Ivermectin of Necator americanus and Ancylostoma ceylanicum
}

\author{
J. C. RICHARDS, J. M. BEHNKE and I. R. DUCE* \\ Department of Life Science, University of Nottingham, University Park, Nottingham \\ NG7 2RD, U.K.
}

(Received 29 November 1994; accepted 26 April 1995)

\begin{abstract}
Richards J. C., Behnke J. M. \& Duce I. R. 1995. In vitro studies on the relative sensitivity to ivermectin of Necator americanus and Ancylostoma ceylanicum. International Journal for Parasitology 25: 1185-1191. Experiments were carried out to compare the sensitivity of Ancylostoma ceylanicum and Necator americanus to ivermectin (IVM) and pyrantel in vitro. Loss of motility and inhibition of ingestion by IVM were compared and $A$. ceylanicum was found to be approximately 40-50 times more sensitive to IVM than $N$. americanus. Both species showed a similar sensitivity to pyrantel. Uptake of $\left[{ }^{3} \mathrm{H}\right] \mathrm{IVM}$ across the cuticle was compared and shown to be unlikely to account for the differences in sensitivity to IVM between the two species.
\end{abstract}

Key words: Ancylostoma ceylanicum; Necator americanus; hookworm; anthelmintic; ivermectin; pyrantel.

\section{INTRODUCTION}

There is much interest in the potential of ivermectin (IVM) as a microfilaricide for the treatment of onchocerciasis (Bennett, Williams \& Dave, 1988), and mass trials against onchocerciasis are being implemented in 12 African and Central American countries. IVM has proven to be a very effective antiparasitic drug and many of the common gastrointestinal nematodes are highly susceptible to IVM at concentrations much lower than those at which other anthelmintics are effective. However, some parasites, including Heligmosomoides polygyrus, Trichuris trichiura, and hookworms (Wahid, Behnke \& Conway, 1989; Whitworth, Morgan, Maude, McNicholas \& Taylor, 1991) have been found to be tolerant to IVM.

In vivo studies on hookworm infections in hamstcrs revealed that Ancylostoma ceylanicum was 300 times more sensitive to IVM than Necator americanus (Behnke, Rose \& Garside, 1993). Previous work (Rajasekeriah, Deb, Dhage \& Rose, 1989) also

\footnotetext{
* To whom correspondence should be addressed.
}

indicated that in a hamster model, Necator was relatively insensitive to IVM.

The difference in IVM sensitivity is of interest in two respects. First, the drug may be used clinically in situations where $N$. americanus and Ancylostoma duodenale are both present in the population and its use may influence epidemiology. Second, if the differential sensitivity of these 2 species reflects a difference in the drug target site, these species of hookworm may provide a good model system to probe further the molecular action of the drug.

In this paper we report in vitro experiments which show that the difference in sensitivity of $N$. americanus and $A$. ceylanicum to IVM can be demonstrated in vitro and is therefore not attributable to the host-parasitc relationship. We further show that the differential responsiveness cannot be explained by differences in the uptake of the drug.

\section{MATERIALS AND METHODS}

Parasites and hosts. Infective larvae of $N$. americanus were obtained from Dr Rajasekariah of CIBA-GEIGY 
Hindustan Ltd, Bombay, India in 1983 and maintained by regular passage through hamsters as described by Sen (1972) and Behnke, Wells \& Brown (1986). A. ceylanicum was also obtained from Dr Rajasekariah and passaged through adult hamsters as described by Garside \& Behnke (1989). Worms of both species were recovered from the host ( $N$. americanus 5 weeks post-infection, $A$. ceylanicum $14-21$ days post-infection), following terminal anaesthesia in chloroform, by cutting open the small intestine and picking out the worms into dishes of warm Hanks's saline (pH 7.0). After several washes with Hanks's saline, approximately $10 \mu \mathrm{l} / \mathrm{ml}$ of penicillin-streptomycin $(10,000 \mathrm{IU} / \mathrm{ml}, 10,000 \mu \mathrm{g} / \mathrm{ml}$, respec-tively) were added and the worms were maintained in Hanks's saline at $37^{\circ} \mathrm{C}$. For incubations of $24 \mathrm{~h}$, worms were incubated in sterile conditions in Rosswell Park Memorial Institute (RPMI 1640 Medium) (GIBCO), containing $10 \mu \mathrm{l} / \mathrm{ml}$ penicillin-streptomycin, $10 \mu \mathrm{l} / \mathrm{ml}$ L-glutamine, $1 \mu \mathrm{l} / \mathrm{ml}$ sodium pyruvate and $0.2 \mu \mathrm{l} / \mathrm{ml}$ monothioglycerol (pH 7.0).

Chemicals. Pyrantel (Pfizer) was taken from a stock solution of $10 \mathrm{mg} / \mathrm{ml}$ pyrantel pamoate in DMSO. Ivermectin (IVM), ivermectin phosphate (IVM-PO $)_{4}$ and $\left[{ }^{3} \mathrm{H}\right]$ ivermectin $\left(\left[{ }^{3} \mathrm{H}\right] \mathrm{IVM}\right)$ were obtained from Merck and Co. (Rahway, U.S.A.). IVM and IVM-PO, were taken from stock solutions of 1 and $2.5 \mathrm{mg} / \mathrm{ml}$, respectively, in DMSO and the $\left[{ }^{3} \mathrm{H}\right] \mathrm{IVM}$ was from a stock with a specific activity of $2.09 \mathrm{MBq} / \mu \mathrm{g} ;\left[{ }^{3} \mathrm{H}\right]$ inulin (specific activity $3.33 \mathrm{GBq} / \mathrm{g}$ ) was purchased from ICN Biochemicals. All drugs were administered in a final DMSO concentration of $1 \% \mathrm{v} / \mathrm{v}$.

Toxicity of IVM and pyrantel. Groups of 10 worms (mixed sexes) were incubated at $37-38^{\circ} \mathrm{C}$ in $1 \mathrm{ml}$ of $1 \%$ DMSO Hanks's saline containing IVM, IVM-PO 4 or pyrantel at a range of concentrations. Preliminary experiments showed that male and female worms of both species were similarly affected by all three anthelmintics under these conditions. Although in the control groups $100 \%$ of the worms remained active, some loss of motility was observed after $3 \mathrm{~h}$ incubation in Hank's and the level of motility rapidly declined after periods of $6 \mathrm{~h}$ or longer. Sterile RPMI 1640 was therefore used as the medium for incubations $>3 \mathrm{~h}$ as the control groups of worms incubated in RPMI retained much higher levels of motility after 6-24 h than in Hanks's saline. The activity of the worms at various times (1-24 h) was compared with controls incubated in $1 \%$ DMSO in Hanks's saline or RPMI 1640. Worms were classed as either active or inactive, and inactive worms were defined as those which showed no motility and did not respond to a mechanical stimulus (gently prodding and lifting the worms with fine watchmaker's forceps).

Uptake of $\left[{ }^{3} H\right] I V M$. Fine wire ligatures (resin-coated copper wire, approximately $100 \mu \mathrm{m}$ diameter) were tied as near to the head and tail of each worm as possible. Damage to the cuticle by the ligatures was assessed microscopically, and visibly damaged worms were discarded. The worms were incubated in groups of 10 (mixed sexes) for $3 \mathrm{~h}$ at $37-$ $38^{\circ} \mathrm{C}$ in $1 \mathrm{ml}$ of incubation medium comprising Hanks's saline/1\% DMSO; $11.44 \mu \mathrm{M}$ IVM; $\left.0.033 \mathrm{MBq} \mathrm{[}{ }^{3} \mathrm{H}\right] \mathrm{IVM}$. Each worm was washed 3 times in Hanks's saline and then placed on filter paper to remove excess moisture. As the $\left[{ }^{3} \mathrm{H}\right] \mathrm{IVM}$ was found to be adsorbed by the wire ligatures, the ends $(0.5 \mathrm{~mm})$ of each worm (both ligatured and unligatured) were removed. After being left to dry overnight on pieces of foil, individual worms were placed in scintillation vials. The worms were solubilized in $100 \mu \mathrm{l}$ of $2.5 \mathrm{M} \mathrm{NaOH}$ for 1-2 h. $\mathrm{HCl}, 100 \mu \mathrm{l} 2.5 \mathrm{M}$, was then added, followed by $4 \mathrm{ml}$ of scintillation fluid (Packard "Emulsifier Safe" liquid scintillation cocktail for aqueous samples). Radioactivity was measured on a Packard Liquid Scintillation Spectrometer. Results were corrected for quenching and expressed as d.p.m./worm. A number of individual worms were incubated without the radioisotope and then analyzed as above to provide background levels; the d.p.m./worm values given are corrected for background.

Uptake of $\left[^{3} \mathrm{H}\right]$ inulin. As IVM is a highly lipophilic molecule, it readily crosses cellular barriers. Inulin, on the other hand, does not pass across cell membranes, and is not readily taken up by cells. $\left[{ }^{3} \mathrm{H}\right]$ Inulin uptake was therefore used to assess the amount of material taken up from the surrounding medium through ingestion. Ligatured and unligatured worms (mixed sexes) were incubated in $1 \mathrm{ml}$ of Hanks's saline containing $1 \%$ DMSO; $0.0333 \mathrm{MRq}$ $\left[{ }^{3} \mathrm{H}\right]$ inulin for $3 \mathrm{~h}$ then analyzed as above.

Inhibition of $\left[^{3} \mathrm{H}\right]$ inulin uptake. Groups of 10 worms (mixed sexes) were incubated for $24 \mathrm{~h}$ in sterile conditions in either $1 \mathrm{ml}$ of RPMI 1640 or HLac (Hanks's saline containing $5 \mu \mathrm{g} / \mathrm{ml}$ lactalbumin, $0.2 \mathrm{M}$ HEPES, $10 \mu \mathrm{l} / \mathrm{ml}$ penicillin-streptomycin, $0.3 \mathrm{mg} / \mathrm{ml}$ kanamycin, $\mathrm{pH} 7.0$ ) and various concentrations of $\mathrm{IVM}^{-} \mathrm{PO}_{4}$ or pyrantel, then analysed as above.

Statistical analysis of results. Non-parametric statistical procedures were used to analyse the data throughout because a normal distribution of data could not be assumed. The results shown in Figs 1a, b and Fig. 2 are prescnted as mean \% of active worms \pm standard error (S.E.M.). For each different concentration of drug, the mean number of active worms given is derived from the results of 3-6 experiments in which groups of 10 worms were incubated for $3 \mathrm{~h}$ and the number of active worms assessed after 1,2 and $3 \mathrm{~h}$. The results of the radioisotope uptake experiments are arranged into four groups: (i) uptake of $\left[{ }^{3} \mathrm{H}\right] \mathrm{IVM}$, (ii) effect of ligatures on uptake of $\left[{ }^{3} \mathrm{H}\right] \mathrm{inulin}$, (iii) and (iv) effects of IVM and pyrantel on uptake of $\left[{ }^{3} \mathrm{H}\right]$ inulin. Mean d.p.m. values given for each experimental group are derived from the pooled results from the analysis of individual worms. In order to avoid Type I errors arising from multiple comparisons within experiments, a maximum of two a priori hypotheses were examined within each of the different experimental groups. A non-parametric form of the ANOVA test (analysis of variance by ranks) was used throughout the analysis. A two-way ANOVA (Meddis, 1984) was employed to assess the results of the uptake of $\left[{ }^{3} \mathrm{H}\right] \mathrm{IVM}$ experiments (Experiment 1$)$ specifying species $(A$. ceylanicum vs. $N$. americanus) and treatment (ligatured vs. non-ligatured) as the two factors. The following hypotheses were predicted: non-ligatured $>$ ligatured and $A$. ceylanicum $>N$. americanus. A one-way ANOVA was used to test the hypothesis: ligatured<non-ligatured (both species) for the results of the ligature/uptake of $\left[{ }^{3} \mathrm{H}\right]$ inulin experiments (Experiment 2). Similarly, in order to test the hypothesis that IVM and pyrantel inhibited the 
(a)

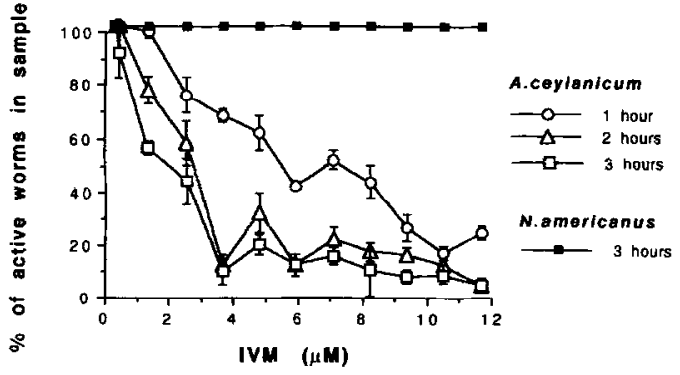

(b)

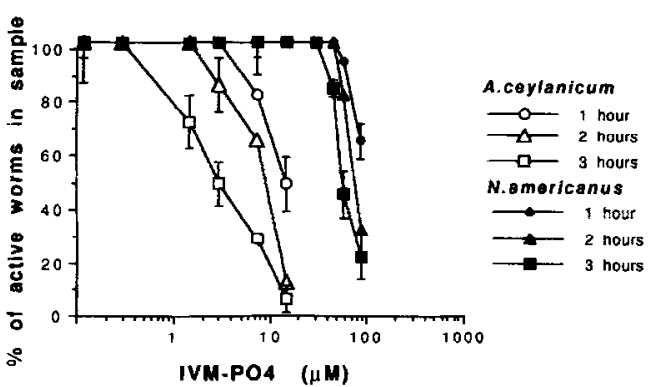

Fig. 1. Comparison of the effects of IVM (Fig. 1a) and IVM- $\mathrm{PO}_{4}$ (Fig. lb) on $\%$ active $A$. ceylanicum and $N$. americanus. Worms were classed as either active or inactive (see Methods) and the data are presented as the mean percentage $( \pm$ S.E.M.) of worms showing activity after 1,2 and $3 \mathrm{~h}$ incubation in IVM or IVM-PO $(n=30-60$ worms). IVM- $\mathrm{PO}_{4}$ was shown to immobilize $N$. americanus dose-dependently (Spearman rank $r_{\mathrm{s}}-0.898, n=18$, $P<0.0001, t=3 \mathrm{~h}$ ). Similarly IVM and IVM-PO ${ }_{4}$ both caused inactivity in $A$. ceylanicum dose-dependently (Spearman rank $r_{\mathrm{s}}-0.80, n=55, P<0.0001, t=3 \mathrm{~h} ; r_{\mathrm{s}}-0.986$, $n=13, P<0.0001, t=3 \mathrm{~h}$, respectively).

uptake of $\left[{ }^{3} \mathrm{H}\right]$ inulin by $A$. ceylanicum and $N$. americanus (Experiments 3 and 4), one-way ANOVA was used to test the prediction that control $>$ IVM/pyrantel treated for each species. For all a priori hypotheses examined, the test statistic $z$ is given as appropriate. Probabilities $(P)$ of 0.05 or less were considered significant.

\section{RESULTS}

Comparison of the effects of IVM and pyrantel on the activity of $\mathrm{A}$. ceylanicum and $\mathrm{N}$. americanus

Over a period of $3 \mathrm{~h}, A$. ceylanicum was found to be equally sensitive to IVM and IVM-PO 4 and was immobilized by IVM or IVM-PO 4 dose-dependently with an approximate $\mathrm{EC}_{50}$ at $3 \mathrm{~h}$ of $1.14 \mu \mathrm{M}, 2.0 \mu \mathrm{M}$ (IVM, IVM- $\mathrm{PO}_{4}$, respectively, $\mathrm{EC}_{50} \mathrm{~S}$ derived from Figs 1a, b).

$N$. americanus was not visibly affected by the standard therapeutic drug IVM at the range of concentrations used $(0.11-11.44 \mu \mathrm{M})$ over a period of $3 \mathrm{~h}$. IVM did not remain in solution above this concentration range or within this concentration

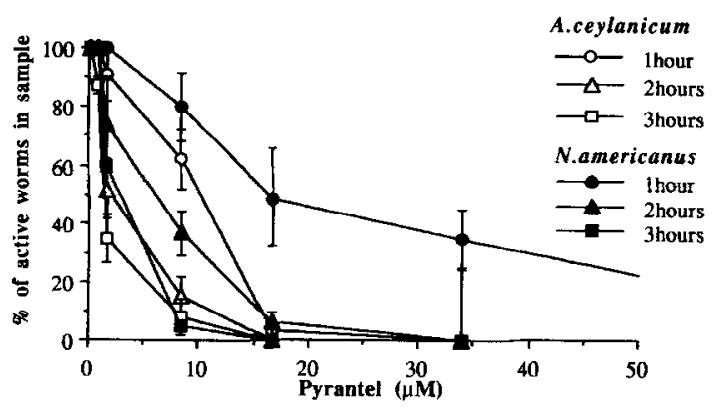

Fig. 2. Comparison of the effects of pyrantel on $\%$ active $A$. ceylanicum and $N$. americanus. Worms were classed as either active or inactive (see Methods) and the data are presented as the mean \% ( \pm S.E.M.) of worms showing activity after 1,2 and $3 \mathrm{~h}$ incubation in pyrantel ( $n=30-60$ worms). $A$. ceylanicum and $N$. americanus were equally sensitive to pyrantel, which immobilized both species dose-dependently (Spearman rank $r_{\mathrm{s}}-0.78, n=46, P<0.0001, t=3 \mathrm{~h} ; r_{\mathrm{s}}$ $-0.75, n=31, P<0.0001, t=3 \mathrm{~h}$, respectively).

range for $>8 \mathrm{~h}$. However, experiments with the more soluble phosphate form of IVM (TVM-PO ${ }_{4}$ ) were carried out and IVM-PO $\mathrm{P}_{4}$ was found to paralyse $\mathrm{N}$. americanus dose-dependently, with an approximate $\mathrm{EC}_{50}$ of $55 \mu \mathrm{M}$ after $3 \mathrm{~h}$ (Figs $1 \mathrm{a}, \mathrm{b}$ ).

Even after incubation periods of $24-48 \mathrm{~h}, N$. americanus was not visibly affected by $\mathrm{IVM}-\mathrm{PO}_{4}$ at concentrations of $11.44 \mu \mathrm{M}$ compared with controls incubated in normal media. However, this concentration caused $>90 \%$ inactivity in $A$. ceylanicum after $3 \mathrm{~h}$.

Pyrantel was found to be similarly effective at paralysing $A$. ceylanicum and $N$. americanus dosedependently, with approximate $\mathrm{EC}_{50} \mathrm{~s}$ of 1.34 and 3.5 $\mu \mathrm{M}$ (A. ceylanicum and $N$. americanus, respectively) $(t=3$ h) (Fig. 2).

Uptake of $I^{3} \mathrm{H} J I V M$ by A. ceylanicum and $\mathrm{N}$. americanus

There was no significant effect of ligaturing the worms on the uptake of IVM; however, there was a significant difference between the species with $A$. ceylanicum taking up more $\left[{ }^{3} \mathrm{H}\right] \mathrm{IVM}$ than $N$. americanus (Table 1a). There was no difference in the uptake by male and female worms.

\section{Uptake of $\left[{ }^{3} \mathrm{H}\right]$ inulin by $\mathrm{A}$. ceylanicum and $\mathrm{N}$.} americanus

The ligatures had a significant effect on the uptake of $\left[{ }^{3} \mathrm{H}\right]$ inulin by both $A$. ceylanicum and $N$. americanus (ratio non-ligatured vs. ligatured $7: 1,9: 1$, respectively, Table $1 \mathrm{~b}$ ), proving the effectiveness of the ligatures in preventing the entry of media via anatomical openings (Ho, Geary, Barshun, Sims \& Thompson, 1992). $N$. americanus was more active in 
Table la-The uptake of $\left[{ }^{3} \mathrm{H}\right] \mathrm{IVM}$ by $A$. ceylanicum, $N$. americanus with and without ligatures

\begin{tabular}{|c|c|c|}
\hline Species & $\begin{array}{l}\text { Ligatured } \\
\text { Mean d.p.m. } \\
\pm \text { S.E.M. }(n)\end{array}$ & $\begin{array}{l}\text { Non-ligatured } \\
\text { Mean d.p.m. } \\
\text { 土S.E.M. }(n)\end{array}$ \\
\hline $\begin{array}{l}\text { A. ceylanicum } \\
\text { N. americanus }\end{array}$ & $\begin{array}{r}126 \pm 11.7(33) \\
78 \pm 9.14(39)\end{array}$ & $\begin{array}{r}111 \pm 11.0(53) \\
73 \pm 17.2(28)\end{array}$ \\
\hline \multicolumn{3}{|c|}{ Statistical analysis for predictions } \\
\hline \multirow{2}{*}{\multicolumn{2}{|c|}{$\begin{array}{l}\text { A. ceylanicum } \\
>N . \text { americanus }\end{array}$}} & $\begin{array}{l}\text { Ligatured }<\text { non ligatured } \\
\text { (both species) }\end{array}$ \\
\hline & & $P$ \\
\hline 3.9 & $<0.0008$ & $>0.05$ \\
\hline
\end{tabular}

For statistical analysis see text. d.p.m. = disintegrations per min.

Table $1 \mathrm{~b}$ - the uptake of $\left[{ }^{3} \mathrm{H}\right]$ inulin by $A$. ceylanicum, $N$. americanus with and without ligatures

\begin{tabular}{lcc}
\hline Species & $\begin{array}{c}\text { Ligatured } \\
\text { Mean d.p.m. } \\
\pm \text { S.E.M. }(n)\end{array}$ & $\begin{array}{c}\text { Non-ligatured } \\
\text { Mean d.p.m. } \\
\pm \text { S.E.M. }(n)\end{array}$ \\
\hline A. ceylanicum & $1.05 \pm 2.86(22)$ & $7.17 \pm 2.96(21)$ \\
N. americanus & $5.52 \pm 3.16(23)$ & $51.2 \pm 7.41(51)$
\end{tabular}

Statistical analysis for predictions

Ligatured $<$ Non-ligatured

$z$

\begin{tabular}{lll}
\hline$N$. americanus & 4.74 & $<0.01$ \\
$A$. ceylanicum & 1.86 & $<0.05$
\end{tabular}

For statistical analysis see text. d.p.m. = disintegrations per min.

terms of uptake, and ingested approximately 6 times more $\left[{ }^{3} \mathbf{H}\right]$ inulin than $A$. ceylanicum. In the medium used, the basal level of ingestion of $\left[{ }^{3} \mathrm{H}\right]$ inulin was lower in $A$. ceylanicum than $N$. americanus, suggesting that $N$. americanus is more active in terms of oral uptake under these conditions.

Comparison of the effect of $\mathrm{IVM}^{-\mathrm{PO}_{4}}$ on the uptake of $i^{3} \mathrm{H}$ jinulin by $\mathrm{A}$. ceylanicum and $\mathrm{N}$. americanus

Although $N$. americanus fed more actively than $A$. ceylanicum over a period of 24 h (RPMI \& HLac medium, Tables $2 \mathrm{a}, \mathrm{b}$ ) a significant inhibition of oral uptake of $\left[{ }^{3} \mathrm{H}\right]$ inulin by $\mathrm{IVM}-\mathrm{PO}_{4}$ was demonstrated for both species (Tables $2 a, b$ ).

There was a highly significant difference between the two species with inulin uptake by $A$. ceylanicum being inhibited by much lower concentrations of IVM- $\mathrm{PO}_{4}$ than $N$. americanus (approximate $\mathrm{EC}_{50} \mathrm{~S} 4$ and $0.1 \mu \mathrm{M}, N$. americanus and $A$. ceylanicum, respectively, Tables $2 \mathrm{a}, \mathrm{b}$, Fig. 3 ).

Pyrantel was found to inhibit the uptake of $\left[{ }^{3} \mathrm{H}\right]$ inulin by $N$. americanus, $A$. ceylanicum dose-
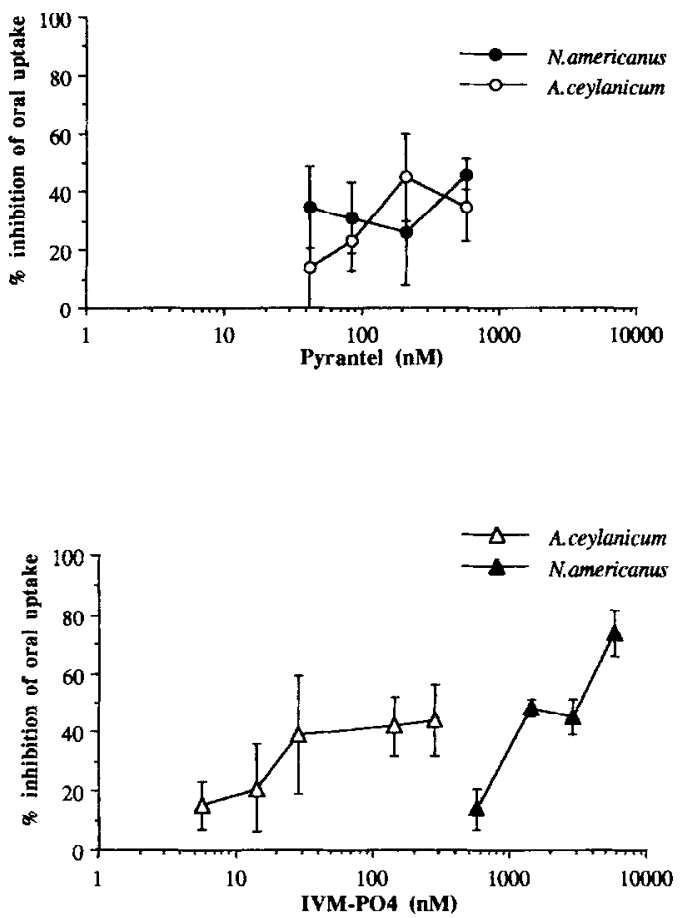

Fig. 3. Comparison of the effects of pyrantel (Fig. 3a) and IVM-PO ${ }_{4}$ (Fig. 3b) on \% inhibition of oral uptake of $\left[{ }^{3} \mathrm{H}\right]$ inulin by $A$. ceylanicum and $N$. americanus $(t=24 \mathrm{~h})$.

dependently (Tables $2 \mathrm{c}$, d, Fig. 3), with both species showing similar sensitivity $\left(\mathrm{EC}_{50} \mathrm{~S}\right.$ approximately 0.6 and $0.4 \mu \mathrm{M}, N$. americanus and $A$. ceylanicum respectively).

\section{DISCUSSION}

The results reported in this paper provide the first direct in vitro comparisons of the sensitivities of two species of hookworm from the important genera Ancylostoma and Necator to IVM. Previous studies (Behnke et al., 1993) showed that in the hamster host, A. ceylanicum was on average 300 times more sensitive to IVM than $N$. americanus. Studies by Rajasekeriah et al. (1989) also reported the relative insensitivity of $N$. americanus to IVM in the hamster model. The results of the above in vitro experiments in which the effects of IVM and pyrantel on motility were assessed support the results of these previous in vivo experiments (Behnke et al., 1993; Rajasekeriah et al., 1989) as $A$. ceylanicum and $N$. americanus were shown to have similar sensitivities to pyrantel, whereas $A$. ceylanicum was found to be approximately 50 times more sensitive to IVM $(t=3 \mathrm{~h})$ than $N$. americanus. The difference in responsiveness to IVM does not appear to be related to response time as concentrations of IVM-PO $\mathrm{P}_{4}$ that immobilized $A$. 
Table $2 \mathrm{a}$-The effect of IVM- $\mathrm{PO}_{4}$ on the uptake of $\left[{ }^{3} \mathrm{H}\right.$ ]inulin by $N$. americanus $(t=24 \mathrm{~h})$

\begin{tabular}{lcc}
\hline IVM $(\mu \mathrm{M})$ & Mean d.p.m. \pm S.E.M. & No. worm' $(n)$ \\
\hline 0 & $279 \pm 17$ & 48 \\
0.57 & $242 \pm 21$ & 15 \\
1.43 & $146 \pm 19$ & 14 \\
2.86 & $153 \pm 16$ & 16 \\
5.72 & $73 \pm 21$ & 6
\end{tabular}

Statistical analysis for prediction

Control $>0.57 \mu \mathrm{M}>1.43 \mu \mathrm{M}>2.86 \mu \mathrm{M}>5.72 \mu \mathrm{M}$

$z \quad P$

$5.72<0.0003$

For statistical analysis see text. d.p.m. = disintegrations per min.

Table $2 \mathrm{~b}$-The effect of IVM-PO $\mathrm{PO}_{4}$ on the uptake of $\left[{ }^{3} \mathrm{H}\right]$ inulin by $A$. ceylanicum $(t=24 \mathrm{~h})$

\begin{tabular}{ccc}
\hline IVM (nM) & Mean d.p.m. \pm S.E.M. & No. worms $(n)$ \\
\hline 0 & $92 \pm 9$ & 26 \\
28.6 & $60 \pm 11$ & 7 \\
143 & $53 \pm 8$ & 14 \\
286 & $60 \pm 7$ & 23
\end{tabular}

Statistical analysis for prediction

Control > 28.6 nM > $143 \mathrm{nM}>286 \mathrm{nM}$

$P$

2.59

$<0.0045$

For statistical analysis see text. d.p.m. = disintegrations per min.

ceylanicum in $3 \mathrm{~h}(1.14 \mu \mathrm{m}, 50 \%$ worms immobilized) had no detectable effect on $N$. americanus over $24 \mathrm{~h}$.

The experiments reported here used concentrations $\geqslant 1 \mu \mathrm{M}$, which have been previously criticized as being unrepresentatively high compared to effective in vivo concentrations (Geary, Klein, Vanover, Bowman \& Thompson, 1992; Geary, Sims, Thomas, Vanover, Davis, Winterrowd, Klein, Ho \& Thompson, 1993). The difference in sensitivity between the two species in vitro is also relatively lower than the difference in sensitivity shown in vivo (A. ceylanicum 40-50 times more sensitive than $N$. americanus in vitro, compared to a 200-300-fold difference in vivo).

When comparing these in vitro experiments with experiments carried out in vivo, it is important to take into account a number of factors. For example, the in vitro experiments required a dose of IVM that had an acute physiological effect, resulting in a single endpoint (e.g. loss of motility) being demonstrated within the limited timescale of a few hours. In comparison, in vivo it is likely that a given drug affects worm viability by inhibiting or interfering with a range of processes in the parasite, e.g. inhibition of egg production, feeding, or movement.
Table 2c-the effect of pyrantel on the uptake of $\left[{ }^{3} \mathrm{H}\right]$ inulin by $N$. americanus $(t=24 \mathrm{~h})$

\begin{tabular}{ccc}
\hline Pyrantel (nM) & Mean d.p.m. \pm S.E.M. & No. worms $(n)$ \\
\hline 0 & $243 \pm 51$ & 9 \\
42 & $160 \pm 36$ & 9 \\
84 & $169 \pm 29$ & 10 \\
210 & $180 \pm 44$ & 7 \\
420 & $131 \pm 14$ & 9
\end{tabular}

Statistical analysis for prediction

Control $>42 n M>84 n M>210 n M>420 n M$

$\begin{array}{cc}z & P \\ 1.71 & <0.0401\end{array}$

For statistical analysis see text. d.p.m. = disintegrations per min.

Table 2d-The effect of pyrantel on the uptake of $\left[{ }^{3} \mathrm{H}\right]$ inulin by $A$. ceylanicum $(t=24 \mathrm{~h})$

\begin{tabular}{ccc}
\hline Pyrantel (nM) & Mean d.p.m. \pm S.E.M. & No. worms $(n)$ \\
\hline 0 & $140 \pm 17$ & 5 \\
42 & $121 \pm 32$ & 5 \\
84 & $109 \pm 14$ & 7 \\
210 & $78 \pm 22$ & 6 \\
420 & $93 \pm 17$ & 8
\end{tabular}

Statistical analysis for prediction

Control $>42 n M>84 n M>210 n M>420 n M$

$$
z \quad P
$$

$$
1.99<0.0202
$$

For statistical analysis see text. d.p.m. = disintegrations per min.

In vivo experiments with IVM also tend to involve much longer periods of exposure to the drug. For example, Campbell \& Benz (1984) found that the anthelmintic efficacy of IVM in cattle persisted for 2 weeks after treatment. Similarly, the microfilaricidal activity of IVM was shown to persist in rodents for at least 30 days after a single dose (Zahner, Sanger, Lammler \& Muller, 1987).

Using a micromotility meter, Geary et al. (1993) demonstrated that the motility of Haemonchus contortus was affected by concentrations of IVM $\geqslant 10^{-8} \mathrm{M}$, much lower than the concentrations of IVM at which loss of motility could be determined by observation $\left(10^{-6} \mathrm{M}\right)$. It is likely that IVM affects motility in $A$. ceylanicum and possibly $N$. americanus at much lower concentrations than those at which the end-point was determined in these experiments. Nevertheless, in these acute in vitro experiments both motility and ingestion showed a significantly greater sensitivity to IVM in $A$. ceylanicum than in $N$. americanus.

The cuticle of nematodes can act as an important permeability barrier and it is possible that the differences in sensitivity to IVM between the two 
species may reflect differences in the ability of the drug to cross the cuticle. This possibility was investigated by measuring the uptake of $\left[{ }^{3} \mathrm{H}\right] I V M$ in worms which were ligatured to prevent the entry of material via anatomical openings (Ho et al., 1992). The results of our experiments suggest two things; first, the rate of IVM uptake across the cuticle is higher for $A$. ceylanicum than $N$. americanus, although the difference in uptake (resulting in an approximate internal IVM concentration $1.6 \times$ greater) is unlikely to be large enough to account for the differences in sensitivity ( 50 -fold) between the two species. Second, as ligatured worms of both species took up considerable amounts of the radiolabelled ivermectin, the results also suggest that the cuticle is an important route of IVM uptake in hookworms. This is supported by studies in which the rate of absorption of drugs across the cuticle was postulated to depend on their lipophillicity (Thompson, Ho, Sims \& Geary, 1993; Ho, Geary, Raub, Barshun \& Thompson, 1990).

Geary et al. (1993) showed that at lower IVM concentrations than those at which motility is affected, IVM caused the paralysis of pharyngeal muscles in $H$. contortus, thus reducing the ingestion of erythrocytes. These authors proposed that this action of IVM may be important in the ability of IVM to control $H$. contortus.

We carried out experiments to establish if IVM caused reduction of ingestion of $\left[{ }^{3} \mathrm{H}\right]$ inulin in $N$. americanus and $A$. ceylanicum and also to determine if there was any difference in the sensitivity to IVM of the ingestion process between the two species. Our results indicate that $\mathrm{IVM}^{-\mathrm{PO}_{4}}$ causes a dose-dependent inhibition of ingestion in both $N$. americanus and $A$. ceylanicum and that the ingestion process in $A$. ceylanicum is approximately 40 times more sensitive to IVM than in $N$. americanus ( $\mathrm{EC}_{50}$ approx. $0.1 \mu \mathrm{M}$, $4 \mu \mathrm{M}$, respectively, $t=24 \mathrm{~h}$ ). In contrast pyrantel inhibited ingestion in both species at the same concentration. The effect of IVM on ingestion has an $\mathrm{EC}_{50}$ approximately 1 order of magnitude less than for loss of motility. This implies some process involved in ingestion; possibly the action of the pharyngeal muscle is differentially affected by IVM.

It has been determined that the primary physiological effect of ivermectin is an increase in permeability of cell membranes to chloride ions (Turner \& Schaeffer, 1989). Specific high affinity avermectin binding sites have been identified and characterized in Caenorhabditis elegans (Schaeffer \& Haines, 1989; Cully \& Paress, 1991; Cully, Vassilatis, Liu, Paress, Van Der Ploeg, Schaeffer \& Arena, 1994) and a clear correlation has been shown between the binding affinity of a series of avermectin analogues for $C$. elegans membranes and in vivo efficacy, suggesting that the binding site is physiologically important (Rohrer, Meinke, Hayes, Mrozik \& Schaeffer, 1992). It is therefore possible that the differential sensitivity to ivermectin observed between $A$. ceylanicum and $N$. americanus may reflect differences in chloride channels or chloride channel binding sites between the two species. This intriguing possibility is currently under investigation in our laboratory using electrophysiological techniques.

Acknowledgements - We thank Professors P. N. R. Usherwood and D. Wakelin for providing facilities for this work in the Department of Life Science, $\mathrm{Mr} \mathrm{D}$. Fox for supervision of the animal housing facilities and Mrs J. Brown and Mr T. Smith for technical assistance. J.C.R. was supported by a post-graduate studentship provided by S.E.R.C. We are also grateful to the Samuel Scott of the Yews Trust for providing financial support towards this project, Pfizer Central Research (Sandwich, U.K.) for a gift of pyrantel pamoate and Merck and Co. (Rahway, NJ, U.S.A.) for gifts of ivermectin, ivermectin phosphate and $\left[{ }^{3} \mathrm{H}\right]$ ivermectin.

\section{REFERENCES}

Behnke J. M., Rose R. \& Garside P. 1993. Sensitivity to ivermectin and pyrantel of Ancylostoma ceylanicum and Necator americanus. International Journal for Parasitology 23: 945-952.

Behnke J. M., Wells C. \& Brown J. 1986. An improved technique for experimental infections with skin penetrating nematode larvae (Necator americanus). International Journal for Parasitology 16: 461-464.

Bennett J. L., Williams J. F. \& Dave V. 1988. Pharmacology of ivermectin. Parasitology Today 4: 226-228.

Campbell W. C. \& Benz G. W. 1984. Ivermectin: a review of efficacy and safety. Journal of Veterinary Pharmacology \& Therapeutics 7: 1-16.

Cully D. F. \& Paress P. S. 1991. Solubilisation and characterisation of a high affinity ivermectin binding site from Caenorhabditis elegans. Molecular Pharmacology 40: $326-333$.

Cully D. F., Vassilatis D. K., Liu K. K., Paress P. S., Van Der Ploeg L. H. T., Schaeffer J. M. \& Arena J. P. 1994. Cloning of an avermectin-sensitive glutamate-gated chloride channel from Caenorhabditis elegans. Nature 371: 707-711.

Garside P. \& Behnke J. M. 1989. Ancylostoma ceylanicum: observations on host-parasite relationship during primary infection. Parasitology 98: 283-289.

Geary T. G., Klein R. D., Vanover L., Bowman J. W. \& Thompson D. P. 1992. The nervous system of helminths as targets for drugs. Parasitology 78: 215-230.

Geary T. G., Sims S. M., Thomas E. M., Vanover L., Davis J. P., Winterrowd C. A., Klein R. D., Ho N. F. H. \& Thompson D. P. 1993. Haemonchus contortus: ivermectin induced paralysis of the pharynx. Experimental Parasitology 77: 88-96.

Ho N. F. H., Geary T. G., Raub T. J., Barshun C. L. \& Thompson D. P. 1990. Biophysical transport properties 
of the cuticle of Ascaris stum. Molecular and Biochemical Parasitology 41: 153-166.

Ho N. F. H., Geary T. G., Barshun C. L., Sims S. M. \& Thompson D. P. 1992. Mechanistic studies in the transcuticular delivery of antiparasitic drugs, 2. Molecular and Biochemical Parasitology 52: 1-14.

Meddis R. 1984. Statistics Using Ranks. A Unified Approach. Basil Blackwell Publishers Ltd, New York.

Pax R. A. \& Bennett J. L. 1991. Neurobiology of parasitic platyhelminths. Parasitology 102: S31-39.

Rajaskeriah G. R., Deb K. R., Dhage K. R. \& Bose S. 1989. Response of adult Necator americanus to some known anthelmintics in hamsters. Annals of Tropic Medicine and Parasitology 83: 279-285.

Rohrcr S. P., Mcinke P. T., Haycs E. C., Mrozik H. \& Schjaeffer J. M. 1992. Photoaffinity labelling of avermectin binding sites from Caenorhabditis elegans and Drosophila melanogaster. Proceedings of National Academy of Science U.S.A. 89: 4168-4172.

Schaeffer J. M. \& Haines H. W. 1989. Avermectin binding in Caenorhabditis elegans. A two-state model for the avermectin binding site. Biochemical Pharmacology 38: 2329-2338.
Sen H. G. 1972. Necator americanus behaviour in hamsters. Experimental Parasitology 32: 26-32.

Thompson D. P., Ho N. F. H., Sims S. M. \& Geary T. G. 1993. Mechanistic approaches to quantitate anthelmintic absorption by gastrointestinal nematodes. Parasitology Today 9: 1 .

Turner M. J. \& Schaeffer J. M. 1989. Mode of action of ivermectin. In Ivermectin and Abamectin (Edited by Campbell W. C.), pp. 73-88. Springer, Berlin.

Wahid F. N., Behnke J. M. \& Conway D. J. 1989. Factors affecting the efficacy of ivermectin against Heligmosomoides polygyrus in mice. Veterinary Parasitology 32: 325-340.

Whitworth J. A. G., Morgan D., Maude G. H., McNicholas A. M. \& Taylor D. W. 1991. A field study of the effect of ivermectin on intestinal helminths in man. Transactions of the Royal Society of Tropical Medicine and Hygiene 85: 232-234.

Zahner H., Sanger I., Lammler G. \& Muller H. A. 1987. Effect of ivermectin in Dipetalonema vitae and Litomosoides carnii infections of Maslomys natalensis. Tropical Medicine and Parasitology 3: 117-122. 